NASA Technical Memorandum 80073

\author{
(NASA-TH-80073) STRESS-INTEASITY PACTORS \\ FOR INTERMAL SUPPACE CRACKS IM CTLIADRICAL \\ PRESSORE TESSEI.S (MASA) 11 P HC AO2/HF 101 \\ 179-27532 \\ CSCL $20 K$ \\ Unclas \\ G3/39 29304 \\ STRESS-INTENSITY FACTORS FOR INTERNAL SURFACE \\ ERACKS IN CYLINDRICAL PRESSIIRE VESSELS
}

J. C. Newman, Jr., and I, S, Raju

JULY 1979
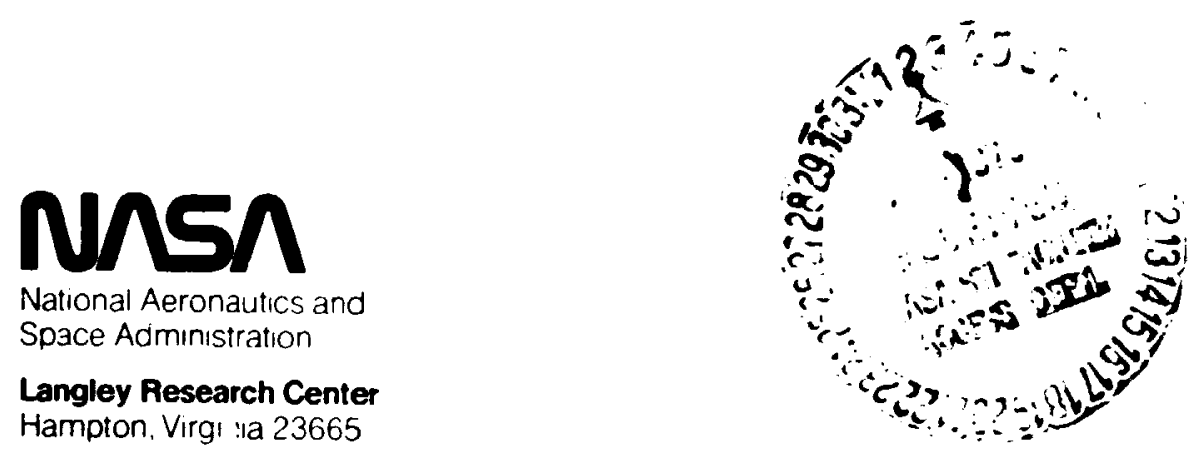


\section{STRESS-INTENSITY FACTORS FOR INTERNAL SURFACE CRACKS IN CYLINDRICAL PRESSURE VESSELS}

J. C. Newman, Jr.

NASA Langley Research Center Hampton, Virginia 23665

and

I. S. Raju

Joint Institute for Advancement of Flight Sciences George Washington University at Langley Research Center Hampton, Virginia 23665

\section{SUMMARY}

Fallures of many pressure vessels have been traced to surface cracks. Accurate stress analyses of these surface-cracked components are needed for reliable prediction of their crack-growth rates and fracture strengths. Because of the complexities of such problems, all investigators have used engineering estlmates or approximate analytical methods to obtain the stress-intensity factors.

A few three-dimensional stress analyses of semi-elliptical surface cracks in pressurized cylinders have been reported recently. However, these investigators considered only an Internal surface crack with a crack-depth-to-crack-1,ngth ratio of $1 / 3$ and a wall-thicknessto-vessel-radius ratio of 0.1 .

The purpose of this paper is to present stress-intensity factors for a wide range of semi-elliptical surface cracks on the instde of pressurized cylinders. The ratio of crack depth to crack length ranged from 0.2 to 1; the ratio of crack depth to wall thickness ranged from 0.2 to 0.8 ; and the ratio of wall thickness to vessel radius was 0.1 or 0.25 . The stress-intensity factors were calculated by a three-dimensional finite-element method. The finite-clement models employed singularity elements along the crack front and 1 inear-strain elements elsewhere. The models had about 6500 degrees of freedom. The stress-intcistity factors were evaluated from a nodal-force method. In this method, the nodal forces normal to the crack plane and ahead of the crack front. were used to obtain the stress-intensity factors.

An empirical equation for the stress-intensity factors was fitted to the results of the present analysis as a function of crack depth, crack length, wall thickness, and vessel radius. The equation applies over a wide range of configuration parameters and was within about 5 percent of the present results.

The present results were compared to other analyses of internal surface cracks in cylinders. The surface-crack configuration had a crack-depth-to-crack-length ratto of $1 / 3$ and a wal.1-thickness-to-vessel-radius ratio of 0.1 . Results from the literature using a boundaryIntegral equation method were in good agreement ( \pm 2 percent) and those from a finite-elcment method were in fair agreenent ( $₫ 8$ percent) with the present results.

The stress-intensity factors and equations presented herein should be useful in correlating fatigue-crack-growth rates and in calculating fracture toughness for the surface crack in a pressurized cylinder. 


\section{Introduction}

Fallures of many pressure vessels have been traced to surface cracks. Accurate stress analyses of these surface-cracked components are needed for rellable prediction of their crack-growth rates and fracture strengths. Because of the complexities of such problems, all Investigators have used engineering estimates or approximate analytical methods to obtain the stress-Intensity factors.

Some engineering estimates for the stress-intensity factors for surface cracks in pressurized cylinders have been made by Underwood [1] and Kobayashi [2]. Their estimates did not Include the effects of wall thickness. Recently, however, Kobayashi, Emery, Polvanich, and Love [3] have estimated stress-intensity factors for internal surface cracks that did include the effects of wall thickness.

A few three-dimensional stress analyses of semi-elliptical surface cracks in pressurized cylinders have been reported recently. Atlur1 ard Kathiresan [4] and McGowan and Raymund [5] used three-dimensional finite-element methods, while Hellot, Labbens, and Pellissier-Tanon [6] used the boundary-integral equation method, to obtain stress-intensity factor variations along the crack front for a limited range of configuration parameters. References [5] and [6] considered only an incernal surface crack with a crack-depth-to-crack-length at1o of ij 3 and a wall-thickness-to-vessel-radius ratio of 0.1 .

The purpose of this paper is to present Mode I stress-intensity factors, calculated by a three-dimensional finite-element method [7-9], for a wide range of semi-elliptical surface cracks in pressurized cylinders. The cracks were located on the inside of the cylinders. The ratio of crack depth to wall thickness ranged from 0.2 to 0.8 ; the ratio of crack depth to crack length ranged from 0.2 to 1 ; and the ratio of wall thickness to vessel radius was 0.1 or 0.25 . The stress-intensity factors were calculated by using a nodal-force method [7-9]. An equation for the stress-intensity factors was aiso developed for a wide range of configuration parameters. The stress-intensity factor varlations along the crack front are presented and, where possible, compared with other solutions from the literature.

2. Symbols

$\mathbf{a}$

b

c

$\mathbf{f}_{\mathbf{c}}$

$\mathbf{F}$

$G_{j}, H_{j}$

$\mathbf{K}_{\mathbf{I}}$

p

Q

$$
R, R_{0}
$$

t

$x, y, z$ depth of surface crack

half-length of pressurized cylinder half-1ength of surface crack

ratio of boundary-correction factors (cylinder to flat plate)

boundary-correction factor for an internal surface crack

boundary-correction factors for $j^{\text {th }}$ stress distribution on crack

stress-intensity factor (Mode I)

internal pressure on the cylinder

shape factor for an elliptisal crack

Inner and outer radii of cylinder

cylinder wall thickness

local Cartesian coordinates centered at crack mouth 


$$
\begin{array}{ll}
X, Y, Z & \text { global Cartesian coordinates } \\
\theta \cdot & \text { angular measurement on cylinder } \\
\sigma_{f} & \text { applied stress on crack surfaces } \\
\dot{q} & \text { parametric angle cf elliptical crack }
\end{array}
$$

\section{Three-Dimensional Analysis}

A surface crack in an internally pressurized cyilnder is shown in figure 1 . The elastic cylinder of wall thickness $t$, internal radius $R$, and length $2 b$, contains a semi-elliptical surface crack of length $2 c$ and depth $a$ on the Inner surface of the cylinder. The stressintensity factors for the surface-crack configurations were obtained by using a threedimensional finite-element analysis.

\subsection{Finite-Element Idealization}

Two types of elements (isoparametric : ' singular [7]) were used in combination to model the cylindrical vessels. Figure $2(a)$ shows a typical finite-element model for an internal surface crack. The model, which employed nearly 6500 degrees of freedom, idealized oneeighth of the vessel $(0 \leq \theta \leq 90$ degrees and $0 \leq x \leq b)$. The isoparametric (1inear-strain, elght-noded hexahedron) elements were used everywhere except near the crack front, where eight singularity elements, eaci. in the shape of a pentahedron, were used [8]. The singularity elements produced a square-root singularity in stress and strain at the crack front. A typical finite-element pattern along the crack plane is shown in figure $2(b)$. The finiteelement models in the neighborhood of the crack were identical to those used in references [8] and [9] for surface cracks in flat plates, except that the models were curved to conform to the destred cylindrical shape. The vessel half-length-to-radius ratio, $b / R$, ranged from 1 to 5 , the $b / c$ ratio ranged from 10 to 50 , and the $t / R$ ratio was 0.1 or 0.25. Further details on modeling and iormulation of the two types of elemeats used are given in references [7-9] and are not repeated here.

\subsection{Boundary Conditions and Applied Loading}

Symetry boundary conditions were applied on the $X=0$ plane; $Y=0$ plane, and $Z=0$ plane, and the model simulated a vessel with two symotric surface cracks (180 degrees apart). The $\mathrm{X}=\mathrm{b}$ plane was free.

The stress-intensity factor solutions were obtained by solving the complementary problem of applied stresses on the crack surfaces. Four applied stress distributicns on the crack surfaces were analyzed: constant, linear, quadratic, and cubic. These stresses, which wcre applied to the crack surfaces as shown in figure $2(\mathrm{c})$, were symetric about the $y=0$ plane and were glven by

$$
\sigma_{j}=\left(\frac{z}{a}\right)^{j} \quad \text { for } f=0 \text { to } 3
$$

where $z$ is measured from the crack mouth toward the crack front. Solutions for these four stress distributions were superimposed to obtain stress-intensity factors for the pressurized cylinder. (These four solutions can be superimposed to obtain stress-intensity factors for other stress distributions, such as those caused by thermal shock.) 


\section{Stress-Intensity Factor}

The Mode $I$ stress-intensity factor, $K_{I}$, at any point along the surface crack was taken to be

$$
K_{1}=\sqrt{\pi \frac{a}{Q}} c_{j}\left(\frac{a}{c}, \frac{a}{t}, \frac{R}{t}, \phi\right)
$$

for $J=0$ to $3, G_{j}$ is the boundary-correction factor corresponding to the $f^{\text {th }}$ stress distribution from eq. (1). Q, the shape factor for an elliptical crack, is $g$ Iven by the square of the complete elliptic integral of the second kind. The vessel length (2b) was always chosen large enough that the length would have a negligible effect on stress intensity $(b / c \geq 10)$.

The stress-intensity factors for a surface crack in an internally pressurjzed cylinder were obtained by approprlate superposition of the results given by eq. (2). For convenlence, the stress-intensity factor was written as

$$
K_{I}=\frac{p R}{t} \sqrt{\pi \frac{a}{Q}} F\left(\frac{a}{c}, \frac{a}{t}, \frac{R}{t}, \phi\right)
$$

where $\mathrm{pR} / \mathrm{t}$ is the hoop stress and $F$ is the boundary-correction factor for a surface crack on the inside of an internally pressurized cylinder. The expression for $F$, in terns of $G_{j}$, was obtained from the first four terms of a power-series expansion of Lame's solution [10] for the hoop stress in an Internally pressurized cylinder. The result is

$$
F=\frac{t}{R}\left(\frac{R_{0}^{2}}{R_{0}^{2}-R^{2}}\right)\left[2 G_{0}-2\left(\frac{a}{R}\right) G_{1}+3\left(\frac{a}{R}\right)^{2} G_{2}-4\left(\frac{a}{R}\right)^{3} G_{3}\right]
$$

where each $G_{j}$ was obtained from the appropriate finite-element solution. The correction factor $F$ includes also the influence of the internal pressure, $P$, acting on the crack surfaces. Values for $F$ were calculated as a function of $a / c, a / t$, and $\phi$ for $t / R$ values of 0.1 and 0.25 . The $a / c$ ratios were 0.2 . 0.4 , and 1 ; and the $a / t$ ratios were $0.2,0.5$, and 0.8 .

The stress-intensity factors from the finite-element models were obtained by using a nodal-force method, details of which are ,iven in references [7] and [9]. In this method, the nodal forces normal to the crack plane and ahead of the crack front are used to evaluate the stress-intensity factors.

\section{Results and Discussion}

In the following sections, results are presented for two symetric semi-elliptical surface cracks on the inside of pressurized cylinders. The stress-intensity factor variations along the crack front for varlous surfacc cracks $(a / c=0.2$ and 1$)$ are presented as a function of $a / t$. An empirical equation for the stress-intensity factor is also developed for a wide range of configuration parameters. An estimate for the stress-intensity factor for a single surface crack is also presented. The stress-intensity factors are comparcd with other solut lors from the 11terature.

\subsection{Semi-Circular Surface Cracks}

Figure 3 shows the boundary-correction factors for two symetric semi-circular surfare cracks $(a / c=1)$ as a function of the parametric angle, $\phi$, and $a / t$ for $t / R=0,0.1$, and 0.25. For $t / R=0$ (flat plate $[8,9]$ ), the $p R / t$ stress in eq. (3) Is replaced by $s_{t}$ a 
remote uniform applied stress. For a fixed $t / R$ ratio, the correction factors are higher for larger a/t ratios. Also, for a fixed a/t ratio, the correction factors are higher for smaller $t / R$ ratios. The maximum correction factor (or stress-intensity factor) occurred at the Intersection of the crack front with the Inner surface $(\phi=0)$.

\subsection{Scmi-Elliptical Surface Cracks}

Figure 4 shows the boundary-correction factors for two symetric semt-elliptical surface cracks $(a / c=0.2)$ as a function of $\phi$ and $a / t$, for $t / R=0,0.1$, and 0.25 . Again, for a fixed $t / R$ rat1o, the correction factors are higher for larger $a / t$ ratios. For a given $a / t$ ratio, smaller $t / R$ ratios gave higher correction factors. In contrast to results for a semi-circular surface crack, the maximum correction factor (or stress-intensity factor) occurred at the maximum depth point $(\phi=\pi / 2)$.

\subsection{Stress-Intensity Factor Equation}

The results shown in figures 3 and 4 suggest that the ratio of the correction factors for a given $t / R$ and those for a flat plate $(t / R=0)$ are nearly independent of the parametric angle, so that the curve for $t / R=0$ can be scaled to approximate the results for $t / R=0.1$ and 0.25 . Figure 5 shows $f_{C}$ (the ratio of $F$ for a given $t / R$ to $F_{0}$ ) as a function of $t / R$. $F_{0}$ is the correction factor for a flat plate $[8,9]$. The ubols (and bars) give the average (and range) of $f_{c}$ for a given valie of a/t with $a / c=0.2,0.4$, or 1 and any value of $\phi$. (For clarity, results for $a / t=0.5$ are not shown.) These results wore found to be closely approximated by

$$
f_{c}=\left[\frac{R_{0}^{2}+R^{2}}{R_{0}^{2}-R^{2}}+1-0.5 \sqrt{\frac{a}{t}}\right] \frac{t}{R}
$$

In figure 5, the upper curve shows the exact limiting solution for $a / c=0$ and $a / t=0$. The upper curve was obtained from Lame's stresses [10] on the inside of the cy] inder and the solution for an edge-crack in a scmi-infinite plate, and is given by eq. (5) with $a / t=0$. The other curves show results from eq. (5) for various a/t ratios.

The stress-Intensity factor for two symmetric surface cracks on the instde of a pressurfied cylinder is given by eq. (3) where the following approximate expression for $F$ has been fitted to the present results and those of roferences [8] and [9]:

$$
\begin{aligned}
& F=0.97\left[M_{1}+M_{2}\left(\frac{a}{t}\right)^{2}+M_{3}\left(\frac{a}{c}\right)^{3}\right] g f_{\phi} f_{c} \\
& M_{1}=1.13-0.09 \frac{a}{c} \\
& M_{2}=0.54+\frac{0.89}{0.2+\frac{a}{c}} \\
& M_{3}=0.5-\frac{1}{0.65+\frac{a}{c}}+14\left(1-\frac{a}{c}\right)^{24} \\
& g=1+\left[0.1+0.35\left(\frac{a}{c}\right)^{2}\right](1-\sin \phi)^{2}
\end{aligned}
$$


and $f_{\phi}=\left[\sin ^{2} \phi+\left(\frac{a}{c}\right)^{2} \cos ^{2} \phi\right]^{1 / 4}$

for $0 \leq \frac{a}{t} \leq 0.8,0<\frac{a}{c} \leq 1, t / R \leq 0.25$, and any $\phi$. Equation (6) 1 within abcut \pm 5 percent of the finite-element results.

An estimate for the stress-intensity factors for a single crack in terms of two symmetric cracks was obtained from an equation (eq. (2)) given in reference [11]. For $a / c=0$ and $t / R=0.1$, the stress-intensity factor for a single crack was about 2 percent lower than that for two symmetric cracks, whereas for $t / R=0.25$ the stress-intensity factor for a single crack was atout 4 percent lower than that for two cracks. For larger a/c ratios the differences are smaller. Thus, eq. (6) can also be ised for a single surface crack without appreciable error.

\subsection{Comparisons with other Solutions}

Figure 6 shows the stress-1ntensity boundary-correction factors obtained by severa] Investigators for a semi-elliptical surface crack $(a / c=1 / 3$ and $a / t=0.8)$ on the inside of a cylindrical vessel with $t / R=0.1$. The crack surfaces were subjected to stress distributions given by eq. (1). The correction factors, $H_{j}$, are those used in references [5] and [6], and are related to $G_{j}$ by

$$
H_{j}=\frac{B_{j} G_{f}}{f_{\phi}} \quad \text { for } j=0 \text { to } 3
$$

where $B_{0}=1, B_{1}=\pi / 2, B_{2}=2, B_{3}=3 \pi / 4$, and $f_{\phi}$ is given by eq. (11). ihe present results are shown as symbols. The results from reference [6], obtaincd from the boundaryIntegral equation method, are shown as solid curves and are in good agreement $( \pm 2$ percent) with the present results for $\phi>\pi / 4$. The dashed curves show the results from reference [5]. Their results were obtained from the finte-element method and were within \pm 3 percent of the present results. (For clarity, the results for $\mathrm{H}_{2}$ were not shown.)

\section{Concluding Remarks}

$\Lambda$ three-disensional finite-element clastic stress analysis was used to calculate stressintensity factors for a wide range of semi-elliptical surface cracks on the inside of cylindrical pressure vessels. The ratio of crack depth to crack length ranged from 0.2 to 1 ; the ratio of erack depth to wall thickness rarged froe 0.2 to 0.8 ; and the ratio of wall thickness to vessel radlus was 0.1 and 0.25 . Singularity elements werc used along the crack front and lincar-strain elements were used elsewhere. The models of these configurations had about 6500 degrees of freedom. A nodal-force method was used to evaluate the stress-intensity factors.

The stress-intensity factors for surface cracks in pressurized cylinders were similar to those calculated for surface cracks in flat plates as a function of the parametric angle. For semi-clrcular cracks, the stress-intensity factors were maximum at the intcrsection of the crack with the inslde surface of the cylinder, but for semi-elliptical cracks the values were largest at the maximum depth point. Larger crack-depth-to-wall-thickness rat los and larger wa11-thickness-to-vessel-radius ratios gave higher stress-intensity factors for all surfacecrack configurations considered. 
The present results were compared to other analyses of internal surface cracks in cylinders. The surface-crack configuration had a crack-depth-to-wall-thickness ratio of 0.8 , a crack-depth-to-crack-length ratio of $1 / 3$, and a wall-thickness-to-vesse1-radius ratio of 0.1. The cracks were subjected to constant, linear, quadratic, and cubic stress distribution on the crack surfaces. The results from a boundary-integral equation method were in good agreement (generally \pm 2 percent) and those from a finfte-element method were in fair agreement ( \pm 8 percent) with the present results.

An empirical equation for the stress-intensity factors for an internal surface crack in a pressurized cylinder was developed to estinate the present results. The equation applies over a wide range of configuration parameters and was within about \pm 5 percent of the present results. The results obtained herein should be useful in correlating fatigue-crack-growth rates and in calculating fracture toughness for the surface crack in a pressurized cylinder.

\section{References}

[1] UNDERWOOD, J. H., "Stress Intensjty Factors for Internally Pressurfzed Thick-Walled Cylinders," Stress inalysis and Growth of Cracks, ASTM STP-513, American Society for Te;ting and Materials, Pp. 59-70 (1972).

(2) KOBAYASHI, A. S., "A Simple Procedure for Estimating Stress Intensity Factors in Regions of High Stress Gradient," Significance of Defects in Welded Structures (T. Kanazawa and A. S. Kobayashi, eds.), University of Tokyo Press, pp. 127-143 (1974).

[3] KOBAYASHI, A. S., EMERY, A. F., POLVANICH, N., and LOVE, W. J., "Inner and Outer Surface Cracks in Internaliy Pressurized Cylinders," J. Pressure Vessel Technology, ASNE, pp. 83-89 (February 1977).

[4] ATLURI, S. N., and KATHIRESAN, K., "Outer and Inner Surface Flaws In Thick-Wa11ed Pressure Vessels," Transacticns of the Fourth International Conference on Structural Mechanics in Reactor Technology, San Francisco, CA (1977).

[5] MCGOWAN, J. J., and RAYMUND, M., "Stress Intensity Factor Solutions for Internal Longitudinal Semi-Elliptical Surface Flaws in a Cylinder under Arbitrary Lnadings," 11th National Symposium on Fracture Mechanics, Blacksburg, VA (June 1978).

[6] Helio;, J., LABbENS, R. C., and PELlissier-TANON, A., "Semi-E1liptical Cracks in the Meridional Plane of a Cylinder Subjected to Stress Gradients," 11 th National Symposium on Fracture Mechanics, Blacksburg, VA (June 1978).

[7] RAJU, I. S., and NEWMAN, J. C., JR., "Three-Dimensional Finite-Element Analysis of Finite-Thickness Fracture Specimens," NASA TN D-8414 (1977).

[8] RAJU, I. S., and NELMAN, J. C., JR., "Improved Stress-Intensity Factors for SemiElliptical Surface Cracks in Finite-I iickness Plates," NASA TM X-72825 (1977).

[9] RAJU, I. S., and NEWIAN, J. C., JR., "Stress-Intensity Factors for a Wide Range of Semi-Flliptical Surface Cracks in Finite-Thickness Plates," Engr. Fracture Mechanics 11, (4), pp. 817-829 (1979).

[10] TIMOSHERKo, S., Strength of Materials, Advanced Theory and Problems, D. Van Nostrand Company, New York (1956).

[11] SHAH, R. C., "Stress Intensity Factors for Through and Part-Through Cracks Originating at Fastener Holes," Mechanics of Crack Growih, ASTM STP-590, American Society for Testing and Materials, pp. 429-459 (1976). 


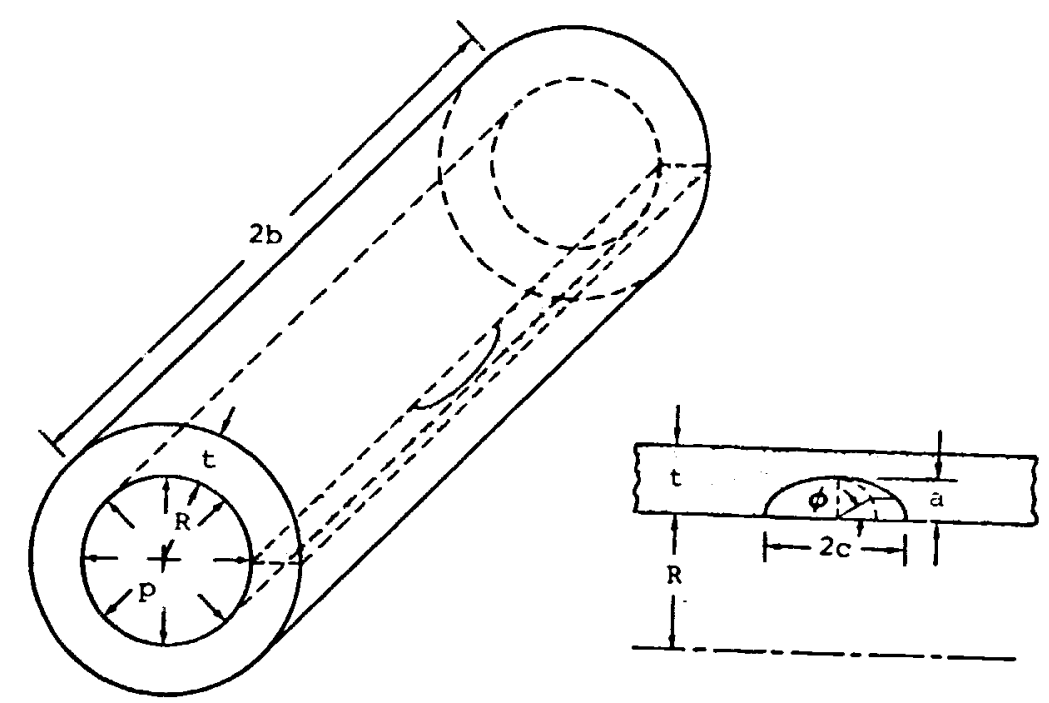

Fig. 1.- Surface crack in an internally pressurized cylinder.
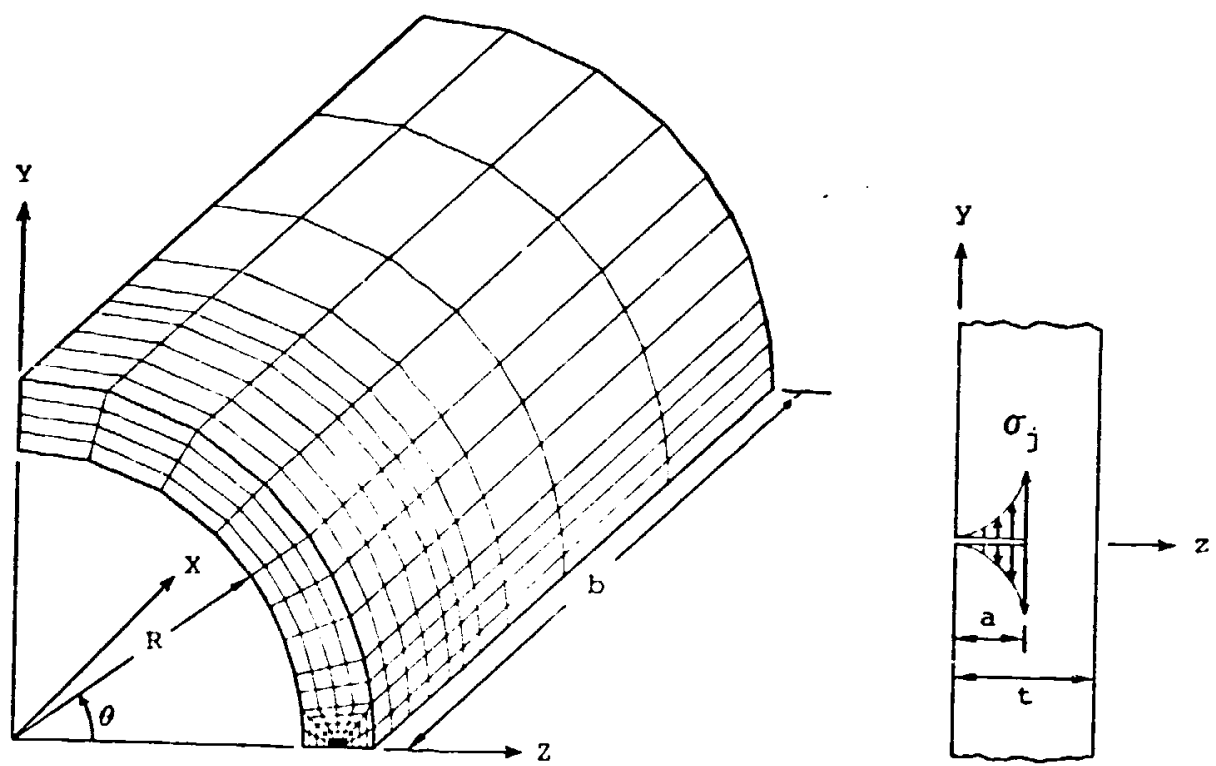

(a) Finite-element model.

(c) Loading on crack surfaces.

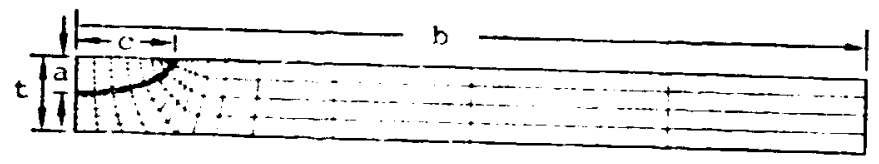

(b) Element pattern on $Y=0$ plane. Fig. 2.- Fi, -nlement molel and loadirg on a semi-clliptical
suri, crack in a cylinder. 


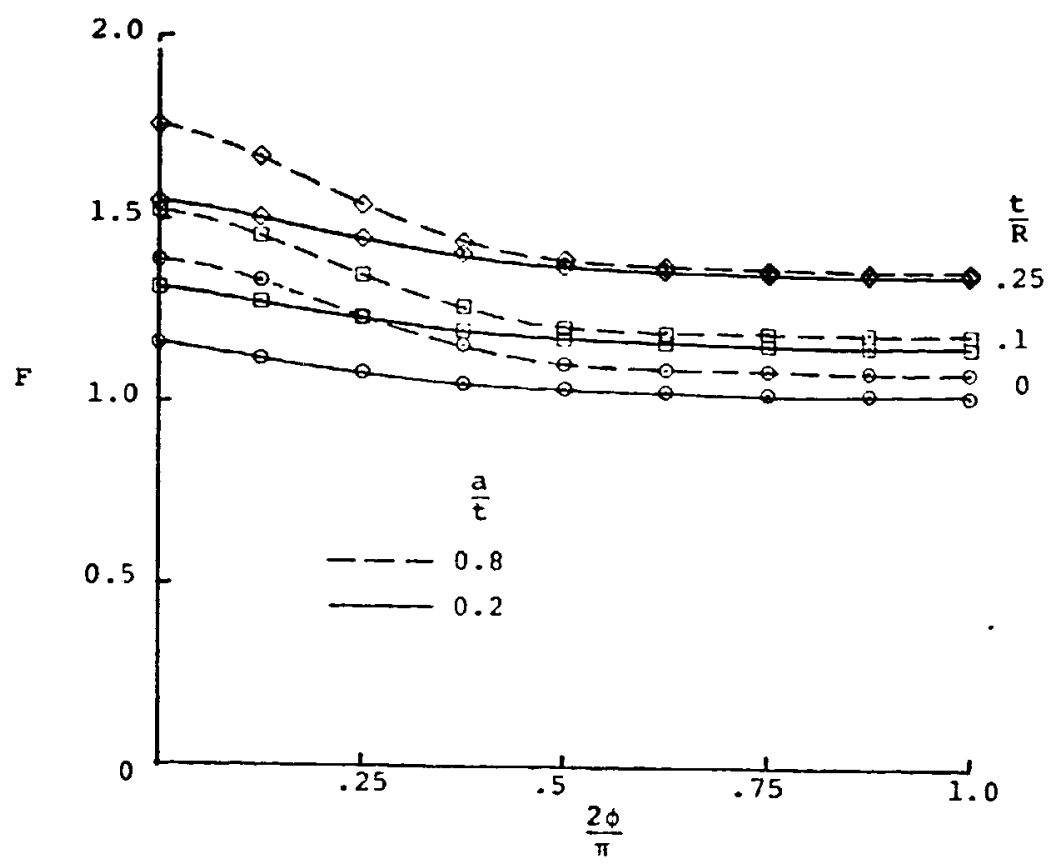

Fig. 3.- Stress-intensity boundary-correction factors along crack front for a semi-circular surface crack $(a / c=1.0)$ in a pressurized cylinder.

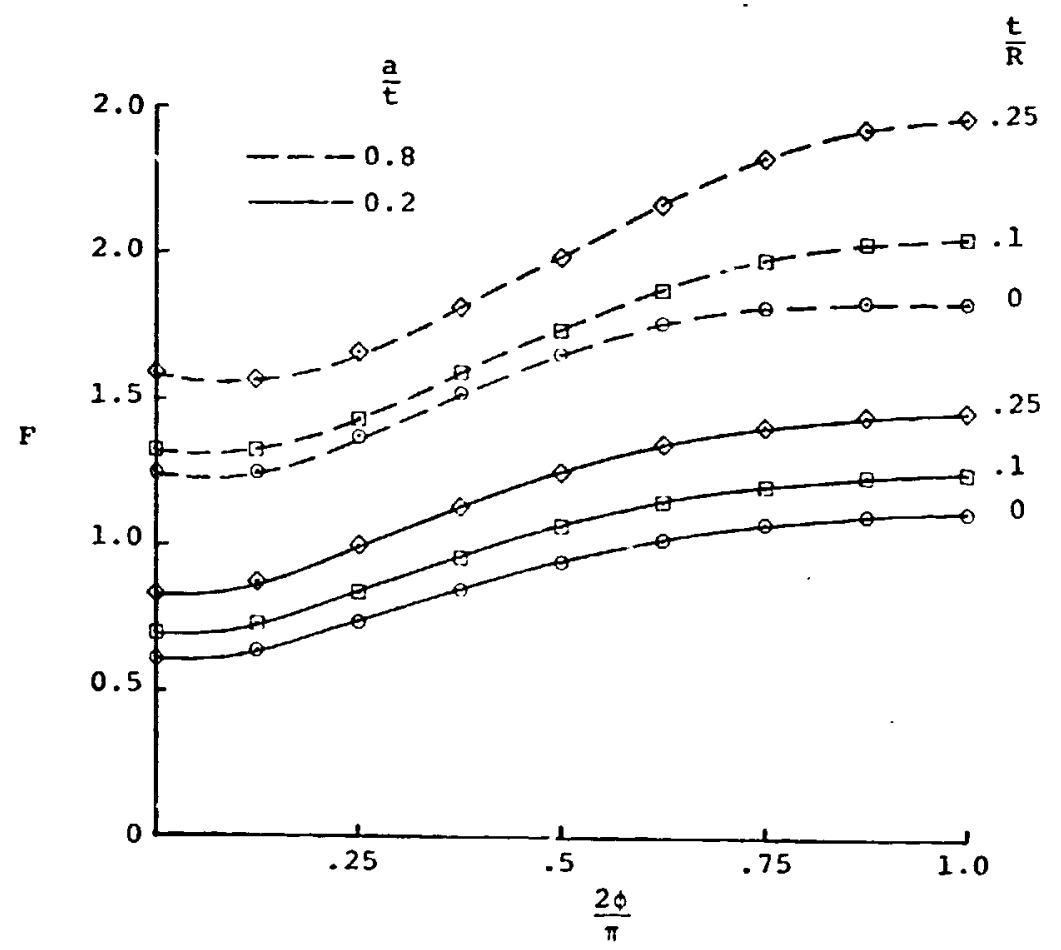

Fig. 4.- Stress-intensity boundary-correction factors along crack front for a seni-clliptical surface crack $(a / c=0.2)$ in a pressurized cylinder. 


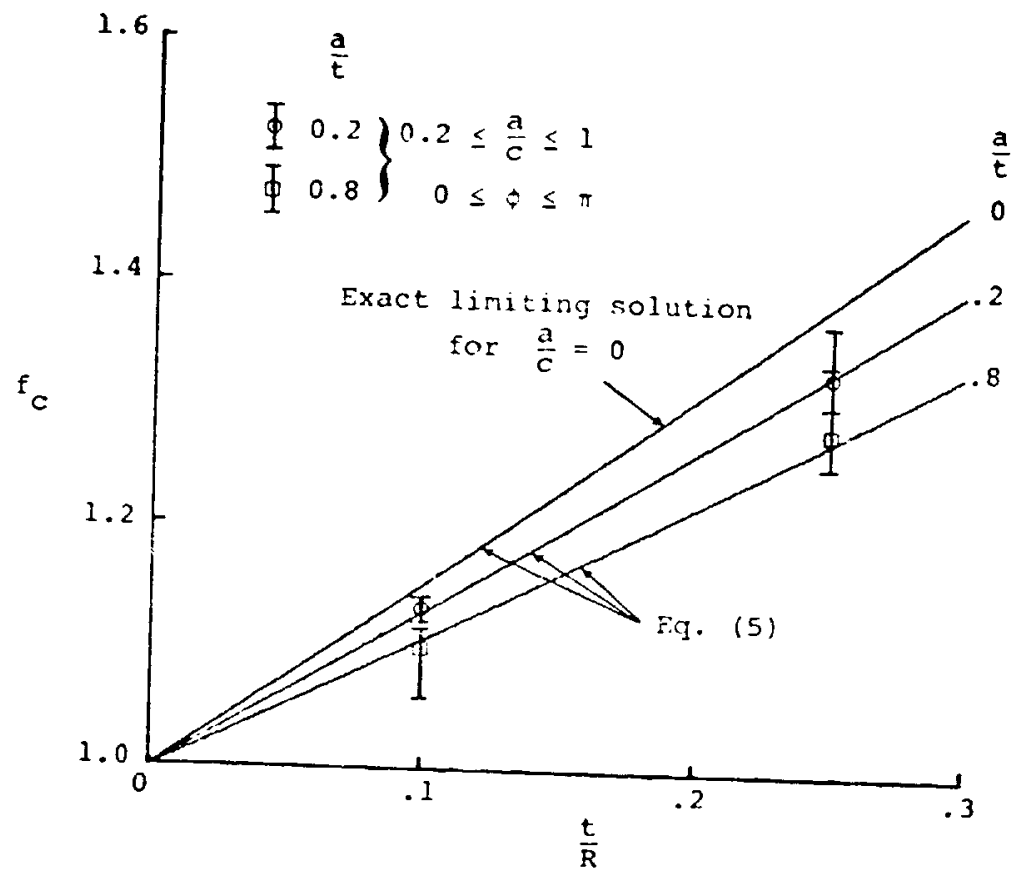

Fig. 5.- Boundary-correction factor for a surface crack in a pressurized cylincier normalized by the correction factor for a surface crack in a flat plate.

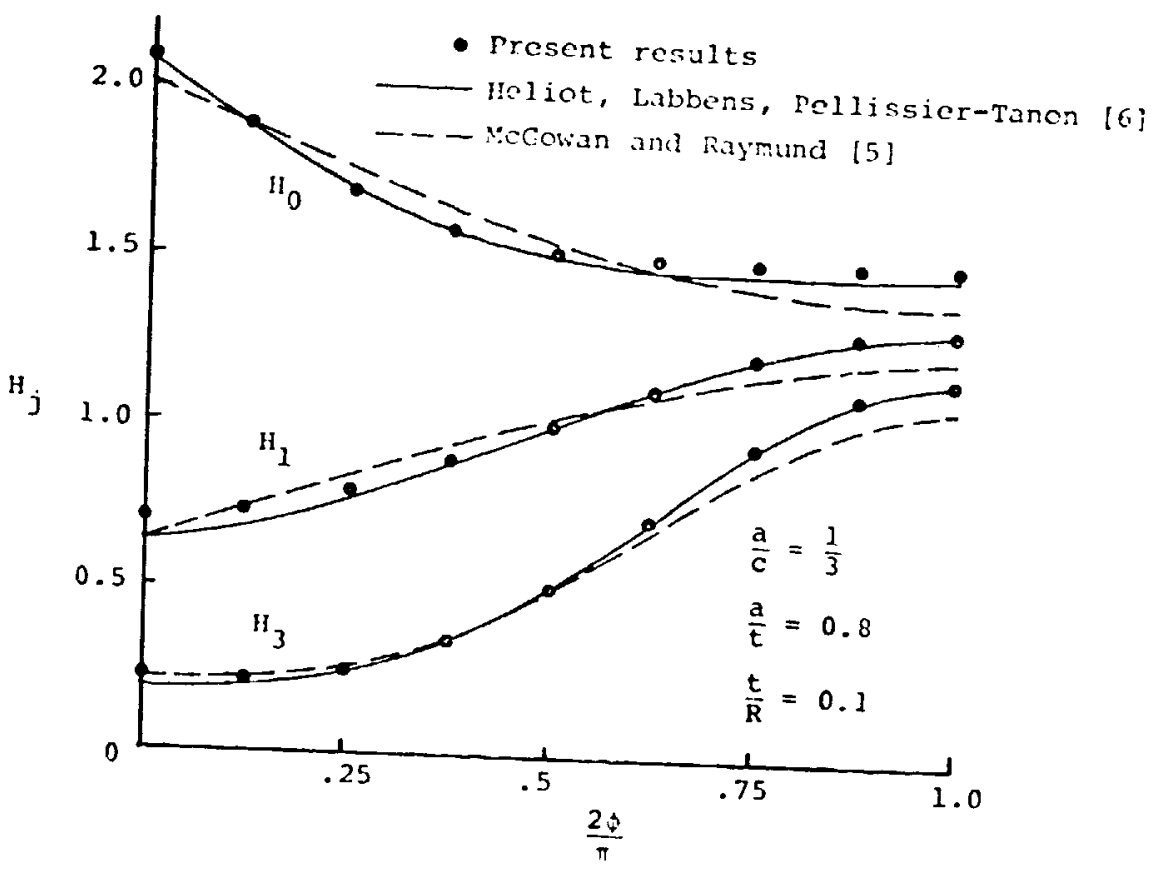

Fig. 6.- Stress-intensity correction-factors computed w scveral methods for a scmi-clliptical surface crack in a cylinacr. 


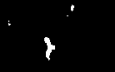

$\dot{8}$
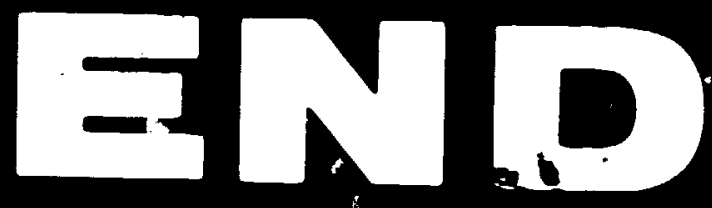

4
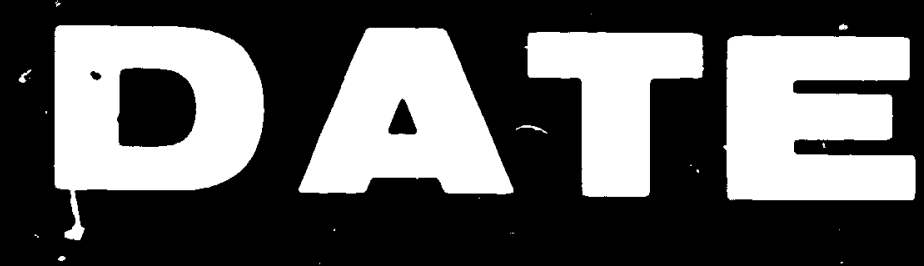

.

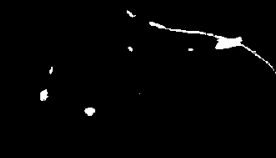

5
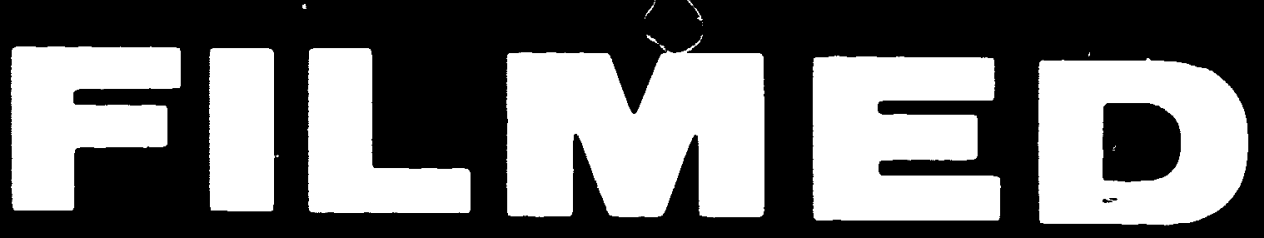

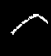

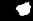
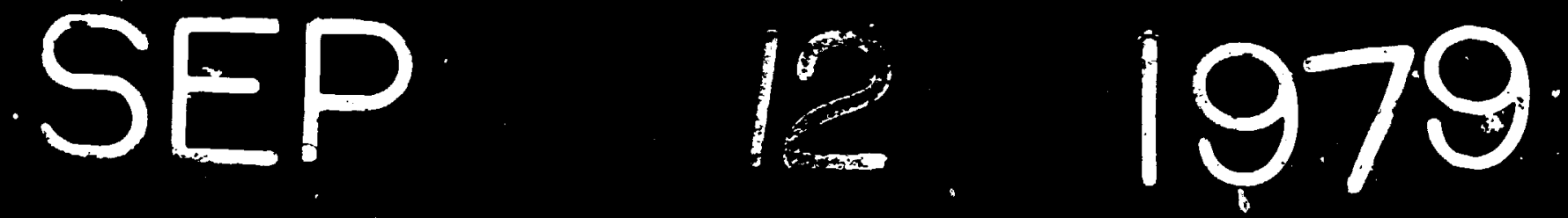